\title{
O CONCEITO DE MEMÓRIA NA OBRA FREUDIANA: BREVES EXPLANAÇÕES
}

\author{
Pâmela Pitágoras Freitas Lima Ferrarini \\ Psicóloga, Doutoranda em psicologia pela UFBA e mestre pelo programa de Pós Graduação em \\ Memória: Linguagem e Sociedade da Universidade Estadual do Sudoeste da Bahia (UESB).
}

Lívia Diana Rocha Magalhães

Docente do programa de Pós Graduação em Memória: Linguagem e Sociedade da Universidade Estadual do Sudoeste da Bahia (UESB). PhD pela Universidade Federal do Rio de Janeiro.

\begin{abstract}
Resumo
O presente artigo tem como objetivo descrever o conceito de memória na obra de Sigmund Freud, precursor da Psicanálise. O tema da memória e suas diferentes manifestações no psiquismo faziam parte das inquietações teóricas de Freud, levando a indagar a respeito do funcionamento desta em seus diversos escritos. Através da análise da obra freudiana e de demais teóricos que debateram a respeito do tema, este estudo teórico visa demonstrar que a memória, na Psicanálise, sempre esteve presente na formulação freudiana da subjetividade humana. A constante evolução da sua teoria permitiu que a memória ganhasse um status cada vez maior, passando de uma análise puramente individual e funcional, para uma dimensão social e cultural, transformando-se num dos alicerces de sua teoria.
\end{abstract}

Palavras-chave: memória; psicanálise; Sigmund Freud.

\section{THE CONCEPT OF MEMORY IN FREUD'S WORK: BRIEF EXPLANATIONS}

\begin{abstract}
This article aims to describe the concept of memory in the work of Sigmund Freud, forerunner of psychoanalysis. The theme of memory and its different manifestations in the psyche were part of the theoretical concerns of Freud, leading to inquire about the functioning of this in his many writings. Through analysis of Freud's work and other theorists who debated on the subject, this theoretical study aims to demonstrate that memory, in psychoanalysis, Freud was always present in the formulation of human subjectivity. The constant evolution of his theory allowed the memory gain increasing status, from a purely individual and functional analysis, for a social and cultural dimension, becoming one of the foundations of his theory.

Keywords: memory; psychoanalysis; Sigmund Freud.
\end{abstract}




\title{
EL CONCEPTO DE MEMORIA EN LA OBRA DE FREUD: EXPLICACIONES BREVES
}

\begin{abstract}
Resumen
Este artículo tiene como objetivo describir el concepto de memoria en la obra de Sigmund Freud, precursor del psicoanálisis. El tema de la memoria y sus diferentes manifestaciones en la psique fueron parte de las preocupaciones teóricas de Freud, lo que lleva a preguntar sobre el funcionamiento de este en sus muchos escritos. A través del análisis de la obra de Freud y otros teóricos que debatieron sobre el tema, este estudio teórico tiene como objetivo demostrar que la memoria, en el psicoanálisis, siempre estuvo presente en la formulación de Freud de la subjetividad humana. La constante evolución de su teoría permitió el aumento de la memoria cada vez mayor estatus, de un análisis puramente individual y funcional, de una dimensión social y cultural, convirtiéndose en uno de los fundamentos de su teoría.
\end{abstract}

Palabras clave: memoria; el psicoanálisis; Sigmund Freud.

\section{INTRODUÇÃO}

O tema da memória sempre esteve presente nos escritos de Freud e na construção da teoria psicanalítica. Este trata da memória em diversos momentos da formulação dos pressupostos da psicanálise, modificando sua concepção na medida em que avançava em sua discussão a cerca do aparelho psíquico e do inconsciente. A problematização da memória e suas diferentes manifestações no psiquismo faziam parte das inquietações teóricas de Freud, desde as relacionadas ao funcionamento da memória e suas distorções, a influência das fantasias nas rememorações e a amnésia que cobre os primórdios dos anos infantis (Freud, 1899/1996).

É objetivo do presente artigo descrever o percurso ao qual Freud desenvolveu sua teorização a respeito do conceito de memória. Trata-se de examinar na obra deste quais são suas concepções a respeito do tema da memória e as diferentes formulações que Freud construiu ao longo de sua obra, destacando-se desta forma a importância deste conceito na elaboração da teoria psicanalítica. O suporte analítico para o desenvolvimento deste trabalho baseiase na leitura de Freud e de teóricos contemporâneos que se dedicaram a discutir tal temática na obra freudiana, visando demonstrar que a memória, na Psicanálise, sempre esteve presente na formulação da subjetividade humana.

\section{A MEMÓRIA PARA FREUD}

A percepção freudiana do aparelho psíquico tem como seu pressuposto central a crença no papel organizador da memória, sendo esta vista como uma 
série de sistemas, dotados de propriedades distintas, signos perceptuais, inconscientes e pré-conscientes (Gabbi Junior, 1993). No percurso freudiano de construção da teoria, sem dúvida é importante destacar que a memória é uma dimensão essencial do escopo psicanalítico.

No final do século XIX, Freud nos apresenta em seus esboços iniciais da teoria a construção daquilo que denominou de um modelo para a memória. 0 mecanismo psíquico parte de um processo de estratificação, em que Freud pensa nas sucessivas transcrições como modo de funcionamento de diferentes fases: a memória não preexiste de maneira simples, mas múltipla, estando registrada em diversas variedades de signos (Freud, 1896/1996). Neste momento de sua obra, Freud destaca as características topológicas do mecanismo psíquico, em que a memória é parte integrante. Seria, então, a possibilidade de acesso, na atualidade, ao evento ocorrido em outras épocas (Farias, 2008).

Somente em 1925, em seu texto sobre o "Bloco Mágico", ao qual faz analogia deste com o aparelho que constitui a base dos sistemas consciente, préconsciente e perceptual, Freud se ocupa em delinear o mecanismo da memória. O bloco mágico é descrito por Freud como sendo formado por uma prancha de cera escura por cima da qual se sobrepõe um papel encerado e uma lâmina de celulóide. Seu mecanismo funciona a partir pela pressão de um instrumento pontiagudo sobre sua superfície. As incisões resultantes tornam-se visíveis pelo contato do celulóide e do papel encerado com a base de cera. Entretanto, quando levantada à folha de cobertura da prancha de cera, a escrita desaparece, sem mais surgir, possibilitando assim fazer uma nova inscrição no Bloco Mágico. De fato, os traços escritos continuam permanentes no aparelho, mesmo que sua base em celulóide possa ser apagada repetida vezes. Estes traços na prancha de cera, em determinada luz, pode ser legível, identificando assim que os traços, mesmos constantemente apagados em dada superfície, continuam fixos em outra. Conforme esclarece Casanave (2008):

De forma mais geral, na comparação com o bloco mágico (...) vemos evidenciada a solução às características aparentemente inconciliáveis e, no entanto, presentes ao mesmo tempo no aparelho psíquico: permanência dos traços e receptividade contínua. Por uma parte, desaparece do bloco mágico apenas separando o celulóide e o papel da cera, restituindo a capacidade de receber novas inscrições; por outra, na cera conservam-se duradoura os rastros do escrito anteriormente. Como no psiquismo, as operações de recepção e conservação distribuem-se em dois componentes diferentes, mas vinculados entre si (pp.78/79). 
Neste modelo é exposto que o aparelho mental possui capacidade receptiva ilimitada para novas percepções, registrando delas traços mnêmicos permanentes, embora não inalteráveis (Freud, 1925/1996). Ele divide a maneira de captação e armazenamento das percepções entre o sistema perceptivo (Pcpt.) e o sistema mnêmico. O sistema Pcpt. recebe os estímulos perceptivos, sendo o responsável por suprir a consciência de toda diversidade das qualidades sensoriais. Já o segundo sistema possui memória e transforma as excitações momentâneas em traços permanentes. A memória é a função que se relaciona com esses traços mnêmicos, que são modificações permanentes dos elementos dos sistemas. Estes são responsáveis por registrar e manter as associações, pois as percepções estão mutuamente ligadas na memória, podendo tornar-se conscientes, mas que produzem seus efeitos quando em estado inconsciente.

A leitura de que o aparelho psíquico na verdade trata-se de um aparelho de memória e de linguagem é apoiado por diversos autores (Farias, 2008; Gabbi Junior, 1993; Major, 2002). Esta compreensão pode ser feita partindo do principio de que este aparelho é constituído de traços mnêmicos, onde a memória pode ser entendida como um texto a ser decifrado, fruto de uma escrita que se faz na condição de reminiscência (Farias, 2008). Para estes autores, Freud representa a memória de dois tipos: a memória simbólica (rememorações), aquela passível de sofrer ação do esquecimento, concernente a história de agrupamento e sucessão de acontecimentos; e da memória propriamente dita, aquela que está no campo do inconsciente.

Podemos então sintetizar algumas idéias sobre a concepção freudiana da memória em algumas proposições (Casanave, 2008): a) aquela capaz de registro, conservação e transformação de experiências em traços mnêmicos, entendidos como processos associativos; b) ela não está associada com a capacidade de percepção ou de consciência, mas sim, tendo sua função localizada nos sistemas pré-consciente e inconsciente; c) múltipla em diversos arquivos e sob signos variados; d) sofre reorganizações de tempos em tempos; e) possui sua eficácia causal, reconhecida no "a posteriori"; f) orientada por representações; e g) identificável com a imaginação e modificação introduzida no material registrado.

Toda a teorização até então formulada pressupõem uma aplicação prática das descobertas do mecanismo da memória, de maneira a apresentar uma modulação para o exercício clínico. Para Freud, então, o objetivo do tratamento 
psicanalítico é preencher as lacunas da memória (Bastos, 1999). Tendo como foco do tratamento as relações entre as lembranças e os esquecimentos e sabendo que há uma não linearidade nos processos mnêmicos, passíveis de serem acrescidos e editados no processo de recordação, sua construção teórica foi modificada e reestruturada ao longo de sua obra.

\section{O BINÔMIO: LEMBRANÇA E ESQUECIMENTO}

É bem claro nos textos freudianos que os processos de esquecer e lembrar passa a revelia do controle racional do sujeito (Romão, 2010). A construção da psicanálise sobre este tema, entretanto, passou por modificações exercidas pelo autor. Em suas obras de 1898 e 1899, Freud apresenta inicialmente aquilo que considera a fundamentação do ato de esquecer e lembrar. Nesta época, argumenta que o processo de esquecimento recebe a influência de diversos fatores, como a constituição psíquica do individuo, a força da impressão do sistema, esforço empregado para recordar, o estado psíquico atual, entre outros e perpassa pela tríade recalque - resistência - deslocamento. Todo ato de esquecimento envolve a relação com o desprazer. Neste processo, a representação a ser lembrada passa pela ação do recalcamento, que é a força pela qual mantém esquecida tais representações. Ao coagir a lembrança do recalcamento, se opera então a resistência, que dificulta a realização de tão processo. Quando então tais representações não conseguem transpor a resistência para apresentar-se, sendo alvo do deslocamento, produzem "representações alternativas" a fim de substituir a lembrança.

Para Farias (2008), Freud apresenta mais de uma forma de operar o esquecimento: a) pelo recalque original, que produzem representações fixas e incapazes de serem dizíveis; b) pelos recalques sofridos ao longo da existência, móvel, passiveis de rememoração; c) amnésia infantil, que ocorre na travessia edípica, não sendo possível delimitar com precisão se as lembranças dos primeiros anos infantis ocorreram de fato, ou se seu conteúdo é acrescido de fantasia; e por fim d) as "lembranças encobridoras".

Sobre o mecanismo das "lembranças encobridoras", Freud (1899/1996) as descrevem como sendo aquelas lembranças irrelevantes que associam seu conteúdo com outras lembranças, as quais busca substituir. Neste texto, as fontes destas lembranças não são diretamente o esquecimento, mas sim a 
omissão de um evento retido na memória. As lembranças sofrem ação de duas forças opostas: aquelas que buscam a lembrança fidedigna e aquela que exerce a resistência e produz o falseamento da recordação. Seu mecanismo de atuação, qual descreve Freud, perpassa pela resistência, sofre a ação do deslocamento e recalque e por fim, é substituída por um conteúdo de fantasia. As lembranças evidenciam o aspecto lacunar da memória, em que as rememorações são da ordem da ficção, não sendo de fato passiveis de serem comprovadas enquanto verdadeiras (Romão, 2010). Estes temas são atualizados por Freud em 1901 em "Psicopatologia da Vida Cotidiana".

Avançando na relação estabelecida entre lembranças e esquecimentos, em 1914, Freud escreve o texto intitulado "Recordar, repetir e elaborar", ao qual articula com mais precisão os mecanismos deste binômio e apresenta uma aplicação no advento da prática psicoterapêutica, apresentando desta forma a importância da transferência neste processo. É neste momento que Freud apresenta uma mudança no mecanismo exercido pela memória, evidenciando ainda mais seus componentes inconscientes.

Freud acrescenta na sua teorização o conceito de repetição, ou como descrito por ele neste texto, de "compulsão à repetição". Este ato de repetir é para Freud, uma forma de recordar em ato (acts it out). Ou seja, o indivíduo não mais rememora o que esqueceu ou reprimiu, mas sim reproduz enquanto uma ação, repetindo sem necessariamente saber que o faz. Esta descoberta evidencia um avanço na questão da memória, já que demonstra pela tríade a funcionalidade da memória pela via inconsciente.

E como se opera esta nova elaboração de Freud para o mecanismo da lembrança? É apresentado pelo autor que o indivíduo, ao invés de recordar, ele repete em forma de ação, e isso ocasiona devido à influência da resistência. Mas o que seria então o conteúdo desta repetição? São todas as inibições, traços patológicos e seus sintomas, são forças que ocorrem na atualidade. Também o papel da resistência é facilmente identificado. Quanto maior é a resistência, mais extensivamente a atuação/repetição (acts it out) substituirá o recordar. As resistências determinam a seqüência do material que deve ser repetido, retirando este arsenal do passado (Freud, 1914/1996).

Ao focar no tratamento, Freud neste momento abandona duas vertentes para descrever uma mudança na orientação para a técnica psicanalítica (Romão, 2010). Sua primeira vertente de tratamento, priorizava a lembrança como forma 
de descarregar o afeto pela via consciente. Em um segundo momento, já não mais recorrendo à hipnose, passa-se a focar no discurso que havia ficado recalcado e não podia ser lembrado ou dito, já que o falar e repetir poderiam ser os passos do sujeito em análise. Por fim, descobre, a partir da técnica da associação livre, o que o analisando deveria falar livremente o que the ocorre no pensamento e através da interpretação das resistências, em que é vencida pelo paciente no processo da análise, este possa relacionar então as situações recordadas e as vinculações esquecidas sem dificuldades.

E como fazer para suspender esta cadeia de acontecimentos, do recordar e repetir? Neste momento então é que se inscreva o exercício da transferência, que vai proporcionar ao analisando a capacidade de executar a elaboração. 0 primeiro passo é apresentar ao analisando que ele é evidenciado através da resistência, e após este processo, passar a familiarizar-se com esta. Somente após o tempo desta apreensão, é que o analisando pode enfim elaborar tal repetição.

Freud acrescenta um novo personagem neste binômio do lembrar/esquecer, que é o papel do analista e da transferência, em que as recordações e esquecimentos passam a ser a matéria prima do tratamento psicanalítico. A transferência tem papel fundamental, já que esta é um fragmento da repetição e sua possibilidade também é veiculada à repetição. É matéria determinante, já que o tratamento só acontecerá por conta da própria repetição. A transferência então cria uma região intermediária entre o sintoma e a vida real, através do qual a transição de uma para a outra é efetuada. A partir das reações repetidas exibidas pela transferência, se é levado ao longo dos caminhos familiares até o despertar das lembranças, que aparecem com poucas dificuldades, após a resistência ter sido superada. E este primeiro passo de superar tal resistência se opera na relação terapêutica (Freud, 1914/1996).

Entretanto, tatear tudo isso é tarefa difícil, sobretudo porque os tempos de recordar, repetir e elaborar são singulares, funcionando de modo diferente e variado para cada sujeito (Romão, 2010). Antes desta inovação no tratamento, e da elevação da importância da transferência no processo de análise, a orientação se dava através da resistência, sem a técnica da interpretação. Como sinaliza Freud (1914/1996):

Finalmente, desenvolveu-se a técnica sistemática hoje utilizada, na qual o analista abandona a tentativa de colocar em foco um momento ou problema específicos. Contenta-se em estudar tudo o que se ache 
presente, de momento, na superfície da mente do paciente, e emprega a arte da interpretação principalmente para identificar as resistências que lá aparecem, e torná-las conscientes ao paciente. Disto resulta um novo tipo de divisão de trabalho: o médico revela as resistências que são desconhecidas ao paciente; quando estas tiverem sido vencidas, o paciente amiúde relaciona as situações e vinculações esquecidas sem qualquer dificuldade (p. 163).

Os lugares do analista e da transferência permitem ao sujeito em análise superar a resistência, descortinando os impulsos reprimidos que a alimentam. A tarefa de conduzir o analisando ao processo de elaboração é uma oficio árduo para o analista, apesar de ser a parte do trabalho que traz maiores benefícios ao paciente, e que distinguem a psicanálise de qualquer outro procedimento terapêutico. O instrumento principal para reprimir a compulsão do paciente à repetição e transformá-la num motivo para recordar reside no manejo da transferência, realizado sempre em parceria entre analista e analisando (Freud, 1914/1996).

\section{TEORIA DA MEMÓRIA FREUDIANA ENQUANTO UMA TEORIA DA MEMÓRIA SOCIAL}

Argumentar que a teorização sobre o tema da memória em Freud seja no âmbito individual é no mínimo simplista. Freud (1896/1996), desde os primórdios de seus trabalhos na formulação da psicanálise evidencia a multimodalidade da memória. Para Freud (1895/1996), toda teoria psicológica digna de consideração terá que fornecer uma explicação para a memória. Na construção da teoria psicanalítica, Freud sempre esteve preocupado em indagar e problematizar questões referentes ao âmbito social e cultural, motivo ao qual sua concepção de memória não fugiria a regra. A razão pela qual entendemos a construção freudiana de aparelho psíquico como uma teoria de memória e, por assim dizer, teoria do campo da memória social decorre da matriz conceitual que evidencia como um dos indícios do processo de constituição psíquica a questão do esquecimento e da lembrança, o que somente ocorre na relação interpessoal (Farias, 2008).

Ao longo do processo de formulação de seus constructos teóricos sobre a memória, Freud deixou evidenciado o caráter não intelectual da memória, ao mesmo tempo em que a afasta de um funcionamento mecânico. Ele mostra que a construção da memória não se confunde com a de um instrumento a serviço de 
trocas inter-humanas subseqüentes. A memória já se constitui dentro de um universo que a precede, a saber: a ordem simbólica (Bastos, 1999). O inconsciente é construído e modificado na relação com o outro, ele é relacional, não podendo ser considerado uma instância pertencente a um único sujeito. Assim também é a memória, concebida na relação.

Freud (1921/1996) na organização do conceito da memória ao longo de sua obra, e enquanto pensador dos fenômenos culturais e sociais, evidencia em seu texto "Psicologia dos grupos e análise do ego" que todas as relações que se constituem como temas da pesquisa psicanalítica podem reivindicar serem consideradas como fenômenos sociais e que sua completude é retirada da influência de outras pessoas. E cabe aqui uma ressalva: se Freud constrói uma teoria da cultura e da gênese social, ele não o faz por analogia ao funcionamento do indivíduo; este é que seria de saída, um indivíduo social (Gondar, 2008).

Um aparelho psíquico, ou de memória, nunca é um. Ele é múltiplo, já que é pela alteridade que preside sua constituição e remanejo. É pelas constatações ao longo da teoria psicanalítica, que podemos considerar a teoria da memória em Freud enquanto uma teoria da memória social. Para Major (2002):

\begin{abstract}
A psicanálise - sua teoria, sua prática, sua instituição - é completamente uma ciência do arquivo e do nome próprio, de uma lógica da hipomnésia que explica as lacunas da memória, daquilo que arquiva a lembrança, transformando-a, ou ao contrário que a desarquiva, apaga, destrói; uma ciência também de sua própria história, da de seu fundador, da relação de documentos particulares (ou secretos) com a elaboração de sua teoria e com tudo aquilo que, de maneira subterrânea, pode explicar sua manifestação no mundo (p. 18/19).
\end{abstract}

\title{
REFERÊNCIAS
}

Bastos, A. (1999). Sobre a lembrança: Uma abordagem psicanalítica dos limites estruturais da memória. Psicologia Reflexão e Crítica, 12(3). Disponível em $<$ http://www.scielo.br/scielo.php?script=sci_arttext\&pid=S0102-

79721999000300006\&lng=pt\&nrm=iso $>$. acessos em 05 maio 2011. doi: 10.1590/S0102-79721999000300006.

Casanave, C. M. I. de L. (2008). As tramas de mnemosine: A memória nos primórdios da teoria freudiana. Tese de Doutorado: Instituto de Filosofia e Ciências Humanas da Unicamp, Campinas, SP: [s. n.].

Freud, S. (1895/1996). Estudos sobre a histeria. In Obras psicológicas completas de Sigmund Freud (Vol. 2, pp. 39-270). Rio de Janeiro: Imago. 
Freud, S. (1896/1996). Carta 52. In Obras psicológicas completas de Sigmund Freud (Vol. 1, pp. 281-287). Rio de Janeiro: Imago.

Freud, S. (1898/1996). O mecanismo psíquico do esquecimento. In Obras psicológicas completas de Sigmund Freud (Vol. 3, pp. 249-284). Rio de Janeiro: Imago.

Freud, S. (1899/1996). Lembranças Encobridoras. In Obras psicológicas completas de Sigmund Freud (Vol. 3, pp. 285-306). Rio de Janeiro: Imago.

Freud, S. (1901/1996). Sobre a psicopatologia da vida cotidiana. In Obras psicológicas completas de Sigmund Freud (Vol. 6). Rio de Janeiro: Imago.

Freud, S. (1914/1996). Recordar, repetir e elaborar. In Obras psicológicas completas de Sigmund Freud (Vol. 12, pp. 161-174). Rio de Janeiro: Imago.

Freud, S. (1921/1996). Psicologia de grupos e a análise do ego. In Obras psicológicas completas de Sigmund Freud (Vol. 18, pp. 79-156). Rio de Janeiro: Imago.

Freud, S. (1925/1996). Uma nota sobre o "bloco mágico". In Obras psicológicas completas de Sigmund Freud (Vol. 19, pp. 253-262). Rio de Janeiro: Imago.

Farias, F. R. de (2008). Pensando a memória social a partir da noção de "a posteiori" de Sigmund Freud. Morpheus, 8, 13.

Gabbi Junior, O. F. (1993). A teoria do inconsciente como teoria da memória. Psicologia USP, 4(1-2). Disponível em <http://www.revistasusp.sibi.usp.br/scielo.php?script=sci_arttext\&pid=S16 78-51771993000100010\&Ing=pt\&nrm=iso >. acessos em 05 maio 2011.

Gondar, J. O. (2008). Memória individual, memória coletiva, memória social. Morpheus, 13, 1.

Major, R (2002). Lacan com Derrida. Rio de Janeiro: Civilização Brasileira.

Romão, L. M. S. (2010). Entre limites e giros da memória. Espéculo (Madrid), 45, 1-17.

Contato: pampitagoras@gmail.com,Irochamagalhaes@gmail.com

Recebido em: 16/10/2013

Revisado em: 26/04/2014

Aceito em: $15 / 07 / 2014$ 